\title{
The on-line voyeur: Promises and pitfalls of observing electronic interaction
}

\author{
CHARLES W. HUFF and JONATHON ROSENBERG \\ Carnegie Mellon University, Pittsburgh, Pennsylvania
}

\begin{abstract}
Studies that compare objective data on communication activity to data provided in verbal reports have indicated that verbal report data are not as accurate as one might hope. Researchers of communication have used verbal reports as their primary source of data because it presents a cheap and easy way to collect the data. This paper presents an easy alternative involving the study of electronic communication: a method that allows the collection of objective information on electronic communication, thus avoiding the problems associated with self-reports. The paper reviews the available literature on the accuracy of self-reports of communication, presents the instrument used to collect the objective electronic communication data, and discusses some of the difficulties and limitations encountered in implementing a study using the instrument.
\end{abstract}

How many people have you talked with today? How about this week? Psychologists, sociologists, and other social scientists have often asked questions like these and trusted that their informants would provide useful data. Most of us, if asked these questions by an inquiring social scientist, would attempt to provide a reasonable estimate of our communications. Of course, the problem lies in determining what a reasonable or useful answer is. That is, our informants might in all honesty be attempting to provide useful data, but still be inaccurate in their reports.

This paper is a report on the implementation of a method that allows the collection of objective information on electronic communication, thus avoiding the problems associated with self-reports. In it, we will first review the available literature on the accuracy of self-reports of communication, then present the instrument used to collect the objective communication data, and finally discuss some of the difficulties encountered in implementing a study using the instrument.

\section{Accuracy in Self-Reports of Communication}

Bernard, Killworth, and Sailer have reported on a series of studies they implemented to determine the accuracy with which people report their everyday communication behavior (Bernard \& Killworth, 1977; Bernard, Killworth, \& Sailer, 1980, 1981, 1982; Killworth \& Bernard, $1976,1979)$. They collected both self-reports and objective measures of communication in several social groups, such as deaf persons who used teletype terminals to com-

The people at the ITC were very helpful and tolerant, both during the pretesting and the actual study; this study would not have been a success without their cooperation. Funding was provided by NSF Expres Grant ASC-8617695 to Carnegie Mellon University. Thanks to Lee Sproull, Sara Kiesler, and other members of the Committee for Social Science Research in Computing for advice and support in the design of the study. Correspondence may be addressed to Charles $\mathrm{W}$. Huff, Department of Psychology, St. Olaf College, Northfield, MN 55057. municate, ham radio operators, employees in a research firm, and participants in an electronic conference. Selfreport data were usually collected in the form of answers to mailed questionnaires. Objective data were established either from saved logs of communication (in the teletype and electronic groups) or by mildly obtrusive observation, such as walking around an office complex and noting all participants in conversations. Their comparisons of the self-report and objective data indicate that the people in these groups were, on the average, $50 \%$ accurate in identifying those with whom they had communicated. This accuracy rate occurs across many different indices and in all of the populations studied, and it is not significantly reduced by taking into account such measures as age, gender, or self-report of recall ability.

The conclusion Bernard, Killworth, Kronenfeld, and Sailer (1984) have made is that all these self-report measures are fatally flawed and worthless for research purposes. ${ }^{1}$ In fact, there is evidence that the picture of behavior provided by self-reports can be actively misleading to researchers. Ettema (1985) has shown that self-report measures and objective measures of use of an information system produce different patterns of correlations with other variables (age, income, interest in the system) and lead to different theoretical conclusions.

To correct some of the error associated with self-report measures, Bernard et al. (1984) suggest that keeping diaries or communication logs might help increase accuracy. Nezlek, Wheeler, and Reis (1983) have reported the results of several studies in which diaries were used to structure informants' recall of their interactions. Their typical study involves between 50 and 100 informants who use diaries to report any interactions longer than $10 \mathrm{~min}$. The informants are encouraged to update their diaries daily, and the reported rate of updating is 1.5 times a day, on the average. Many of the informants in these studies are roommates, whose records can be compared with each other's to produce a measure of agreement (i.e., do both 
$\mathrm{X}$ and $\mathrm{Y}$ say that they interacted last night?). Correlations of roommates' estimates of communication ranged from .76 to .81 . These correlations indicate that roommates agreed $58 \%$ to $66 \%$ of the time in their reports. This may indicate an improvement in accuracy (from the 50\% rate) if we can consider roommate-roommate correlations comparable to verbal-report-objective-measure correlations. Still, a $66 \%$ accurate measurement tool seems to leave substantial room for improvement. The evidence so far indicates that we will not be able to improve the accuracy of self-reports much beyond this range.

One approach to the problem of getting accurate reports of communication would involve studying the process by which people remember these sorts of events. This is an active research area (Hasher \& Zacks, 1984; Johnson, 1985; Reiser, Black, \& Abelson, 1985), but it has not yet suggested corrective strategies that researchers might use to increase the accuracy of self-reports.

Of course, the reason researchers rely on self-reports of communication is that objective measures are costly and difficult to implement. For instance, the office observation procedure used by Bernard et al. (1980) requires a full-time commitment during the period of the study and still only samples interactions in each office every $15 \mathrm{~min}$. What is needed are cheap and easy-to-implement objective measures of communication activity that provide reasonably full coverage of communication activity.

There is at least one mode of interaction that would allow for this sort of objective collection of communication data: electronic communication. Electronic mail is becoming a widely used form of communication in many companies and academic institutions (Sproull, 1986). Sproull (1986) and Bernard et al. (1982) asked participants to save all of their electronic mail (incoming and outgoing) and used these saved-mail messages as the objective measures of communication behavior. This provided a relatively easy way to measure with whom participants were talking electronically, and in addition, to measure the content and length of their conversations.

This method does present some problems. Participants may inadvertently delete messages, or forget to save them. Since participants are actively involved in saving their messages, they are constantly reminded that their communication is being observed. The method used in the study reported here escapes these disadvantages in that it monitors electronic communication automatically and unobtrusively. In addition, it should be portable to most other systems that run UNIX or reasonable variants thereof.

\section{Method}

This study of electronic communication took place at the Information Technology Center (ITC), an organization responsible for the design and improvement of the Andrew computing system at Carnegie Mellon University. All 50 members of the ITC use the Andrew system as their main computing environment. All were asked to participate in a study of electronic communication in which they would answer several questionnaires and allow their electronic communication to be monitored. Of them, 38 agreed to participate.

The Andrew environment. Andrew is a computer system that is a joint product of IBM and Carnegie Mellon University. It consists of a network of high-function workstations and file servers, with each individual workstation providing the CPU needed for the operation of that workstation's processes. To the user sitting at a workstation, the file system looks like a standard UNIX hierarchical file system. There are over 300 Andrew workstations available on the campus of Carnegie Mellon University, and the system is used by the students, faculty, and staff. Users on low-function workstations (such as PCs and Macintoshes) can obtain access to the Andrew file and mail systems by connecting to one of a pool of dedicated Andrew workstations acting as server machines. The lowfunction workstation makes requests of the server machine, which processes these requests and transmits the results back to the workstation.

The ITC. The Information Technology Center was established in 1982 by IBM and Carnegie Mellon University to design and develop a system (Andrew) that would support the university's computing needs. The ITC is composed mostly of computer scientists, system designers, programmers, and hardware technicians. There are also support (financial and secretarial) and documentation staff. All of these positions were represented among the 38 people who agreed to participate in the study.

The study. The participants filled out an on-line automated questionnaire, in which they were asked to rate on a 10-point scale their communication with other ITC members in several modes: computer, telephone, paper memos, and face-to-face interaction. They also gave permission for their electronic mail to be monitored.

The monitoring was accomplished in two parts. Whenever a participating user read or transmitted an electronic message, the headers of that message were saved in a designated file on the local disk of the workstation. The headers are a sequence of attribute-value pairs that are prepended to the body of an electronic mail message to provide information to the recipient about the origination and routing of the message. Andrew uses headers as defined in RFC 822 (Crocker, 1982). The headers contain information about the originator of the message, the intended recipients, and the subject as provided by the originator. Note that the actual body of the message was not captured. In order to collect the saved headers from the local disk, every workstation ran a background process every $1 / 2 h$ that read the set of saved headers and transmitted them (as an electronic message) to a designated directory in the central file system. More details on the collection process are contained in the next section.

Headers were collected from the participants for $2 \frac{1 / 2}{2}$ weeks. With 38 people sending and reading mail, 7,230 files of headers were collected over the $2 \frac{1 / 2}{2}$-week period. Each file contained from 1 to 40 headers, with an average of 4 headers per file. Thus, a total of approximately 
29,000 headers were collected over this period. Since headers were generated for both sending and reading a message, each message sent by a participant and read by a participant was represented at least twice in this data. In addition, many messages were sent to several people, and when each of these persons read the message (if a participant), a header was generated. If we assume that each message was represented at least twice, the data represent, at the upper bound, 14,500 messages. Given the suspected high incidence of messages sent to many people, this estimate is probably quite high. Further analysis of the data will provide a better estimate of the amount of message traffic the headers actually represent.

The programs. As mentioned above, information about the transmission and reading of mail messages was collected in the form of mail headers. These headers were written to files on a workstation's local disk and were transmitted routinely by a background process to a central location.

The headers were written to the local disk by a process known as the Message Server (MS). The MS is used by virtually every mail interface on Andrew to provide access to facilities for reading and sending electronic messages. Writing the headers from the MS thus provided a single mechanism for collecting information that was guaranteed to capture information from the widest possible set of mail interfaces, including those run on lowfunction workstations, such as PCs and Macintoshes.

The headers prepended to a message often contain much information that was not of interest for this study. For example, messages that are received frequently contain long sequences of routing information, which indicates the electronic path the message has traveled. The MS could have had knowledge as to which headers were of interest and written only those. This would, however, have made it difficult to make changes to the set of headers desired. Instead, the MS wrote all of the headers to the local disk. In addition, the MS created a new pseudoheader that contains a time stamp for the transaction and some information about the size of the body of the message.

The headers that were saved on the local disk were picked up by a background process that was run every $1 / 2$ h. $^{2}$ This process picked up each set of headers and ran them through a filter to remove unwanted headers. ${ }^{3}$ Each group of headers was then placed into a message and mailed to a directory in the central file system. At this point, the file containing the headers could be deleted. The source files that made up the collection daemon are included in an appendix to this paper.

\section{Difficulties Encountered}

Ethics. One of the concerns present in any observational study is the ethical implication associated with watching people without their knowledge. In this study, we asked the participants for their consent before we monitored their electronic mail, and they were informed of the monitoring process.
All users on the Andrew system have a "preferences" file that allows them to customize their computing environment. The mail interface in this study checked the preferences file of each person logged into the system and copied headers only if this file contained a line giving it permission. Thus, by modifying their preferences file once, a user could give permission to have his or her electronic communication studied.

However, the program presented here can be modified to monitor electronic mail without the consent of the parties involved. The only legitimate reason one might have for studying users' electronic communication without their participation would be that, not knowing about the study, people would be less likely to change their behavior and thus contaminate the data. If one were concerned about this, one could inform the participants, after the fact, that their electronic communication had been monitored, and give them the option of deleting the data that were generated by that monitoring. Even so, we do not think that monitoring electronic communication without peoples' consent would be justified, or that it would be tolerated if discovered.

In addition, the advantage of nonreactivity can perhaps be gained without the cost of violating the rights of the participants in such a study. It is probable that, during the $21 / 2$-week course of this study, most people were at least not actively thinking of the study when they sent or received messages. At least in this community, electronic mail is so central and frequent a part of communication that it is unlikely that participants modified their communications because they knew they were being monitored.

Another ethical problem involved the safeguarding of the data that the participants provided. In order to allow the voyeur to insert the data in the protected directory, all the participants had to have insert access to the directory. However, to keep the data private, only the experimenter could have read access to that directory. In order to provide an additional safeguard, the ability of all users of the system to even list the names of the files in the data directory was restricted. This presented the curious circumstance that the participants who provided data could not even look at their own data. This was, however, a small price to pay in order to protect the privacy of the participants.

Preferences file problems. Several of the difficulties centered on the format used in implementing the authorization to monitor electronic mail. As explained earlier, this was done by asking the participants to place a permission line in their preferences file. One completely unforeseen problem occurred when data from people not involved in the study began appearing in the protected data directory. After some investigation, it was discovered that someone had copied the preferences file of one of the participants, complete with the permission line, thus inadvertently joining the study. Preferences files are often copied from user to user in order to share customized computing environments. In order to avoid this sort of intrusion on unsuspecting users, it would probably be best 
to change the mechanism for implementing permission. Perhaps a file could be established (with universal read, but only experimenter write privileges) that would contain the names or user IDs of the people who had given their permission to be in the study. The voyeur could then read this file to determine if a user was in fact a participant.

Another advantage that this method of implementing permission would provide would be a uniform starting time for the monitoring process. In this study, some people placed the permission line in their preferences file immediately upon being requested to do so. Others took as long as $\mathbf{5}$ days to do this, and still others misspelled the permission line so that the voyeur did not recognize it and excluded them from the study. A centrally maintained permission file would eliminate these problems.

Storing the data. Users of this system should be aware that the files of headers it creates can mount in number rapidly. Remember that each message within the group studied can be represented by at least two header records, one for the sending of the message and one for the reading. In addition, if the message is sent to several people (or to a public electronic bulletin board read by several people), each person who reads the message will create a header record. From our experience with this study (which produced $13 \mathrm{MB}$ of header records), we recommend that the experimenter have available at least $250 \mathrm{~K}$ of storage available for each person-week of electronic mail that is monitored. Our estimate is based on the traffic observed in this study, which would probably be considered a high-traffic electronic mail system. The Andrew system, for instance, has over 1,700 public electronic bulletin boards available for users to read.

\section{Conclusions}

By comparing the participants' reported electronic mail use and their actual mail use, we will be able to determine the accuracy we can expect from self-report measures of this kind. However, the on-line voyeur provides, for electronic communication, an easier method of assessing communication and constructing maps of electronically constituted social networks. The data produced are straightforward and easy to code, and they are not significantly more cumbersome to analyze than are selfreport measures. Given the ease of this sort of monitoring and the potential unreliability of self-report measures, we would suggest that an electronic monitor be substituted for self-report measures of electronic communication whenever feasible.

Of course, what the social scientist would like is automatic methods to measure communication in other modes. This may be straightforward in telephone communication, as long as calls are centrally processed. Face-to-face communication could be automatically tracked by soundactuated tape recorders. The ethical problems that these methods create are of course more difficult than those found in electronic communication. On most computer systems, people have unique user IDs that can be tied to data collection and used for permission and identification. In telephone or face-to-face monitoring, it is the physical object (a particular telephone) or place (a particular office) that produces the data, and identifying participantswhether for permission or for data analysis-will be more problematic. We have worked out most of these problems in the study of electronic communication, but there is always more to do.

\section{REFERENCES}

Bernard, H. R., \& Killworth, P. D. (1977). Informant accuracy in social network data II. Human Communication Research, 4, 3-18.

Bernard, H. R., Killworth, P. D., \& Sailer, L. (1980). Informant accuracy in social network data: IV. A comparison of clique-level structure in behavioral and cognitive data. Social Networks, 2, 191-218.

Bernard, H. R., Killworth, P. D., Sailer, L. (1981). A review of informant accuracy in social network data. In H. J. Hummall \& W. Sodeur (Eds.), Modelle für Ausbreitungsprozesse in Sozialen Strukturen. Duisberg, West Germany: Sozialwissenschaftlichen Kooperative.

Bernard, H. R., Killworth, P. D., SAiler, L. (1982). Informant accuracy in social network data: $V$. An experimental attempt to predict actual communication from recall data. Social Science Research, 11 , $30-66$.

Bernard, H. R., Killworth, P. D., Kronenfeld, D., Sailer, L. (1984). On the validity of retrospective data: The problem of informant accuracy. Annual Review of Anthropology, 13, 495-517.

Crocker, D. H. (1982). RFC 822: Standard for the format of ARPA internet text messages. University of Delaware, Department of Computer Science.

ETTEMA, J. S. (1985). Explaining information system use with systemmonitored vs. self-reported measures. Public Opinion Quarterly, 49, 381-387.

Hasher, L., \& ZACKS, R. T. (1984). Automatic processing of fundamental information: The case of frequency of occurrence. American Psychologist, 39, 1372-1388.

Johnson, M. K. (1985). The origin of memories. In P. C. Kendal (Ed.), Advances in cognitive-behavioral research and therapy (Vol. 4, pp. 1-27). New York: Academic Press.

Killworth, P. D., \& BerNARD, H. R. (1976). Informant accuracy in social network data. Human Organization, 35, 269-286.

Killworth, P. D., BerNARD, H. R. (1979). Informant accuracy in social network data: III. A comparison of triadic structures in behavioral and cognitive data. Social Networks, 2, 19-46.

Nezlex, J. B., WheEler, L., \& ReIS, H. T. (1983). Studies of social perception. In H. T. Reis (Ed.), Naturalistic approaches to studying social interaction (New Directions for Methodology of Social and Behavioral Science No. 15, pp. 57-73). San Francisco: Jossey-Bass.

Reiser, B. J., Black, J. B., \& Abelson, R. P. (1985). Knowledge structures in the organization and retrieval of autobiographical memories. Cognitive Psychology, 17, 89-137.

Sproull, L. (1986). Using electronic mail for data collection in organizational research. Academy of Management Joumal, 29, 159-169.

\section{NOTES}

1. Cognitive psychologists have concluded that people "demonstrate remarkable knowledge of the frequency of occurrence of all events so far tested" (Hasher \& Zacks, 1984). Hasher and Zacks have studied knowledge of the frequency of words, names, professions, and sources of mortality. One might therefore expect that people would show "remarkable knowledge" about frequency of communication. This empirical disagreement has yet to be resolved.

2. The process was started using the cron facility of UNIX.

3. The filter was an awk script, and is included in the Appendix. 
The Collection Daemon: statd

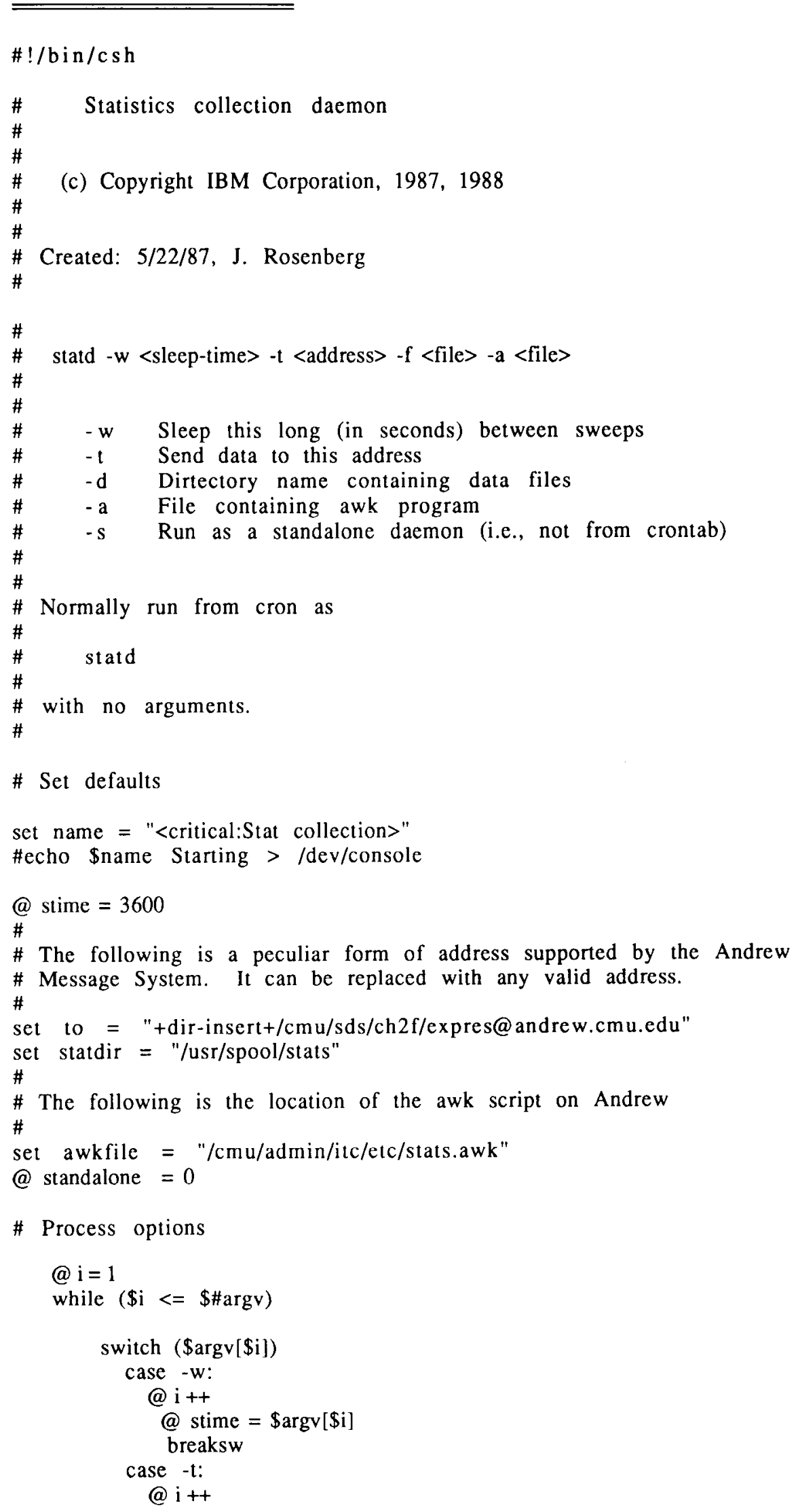




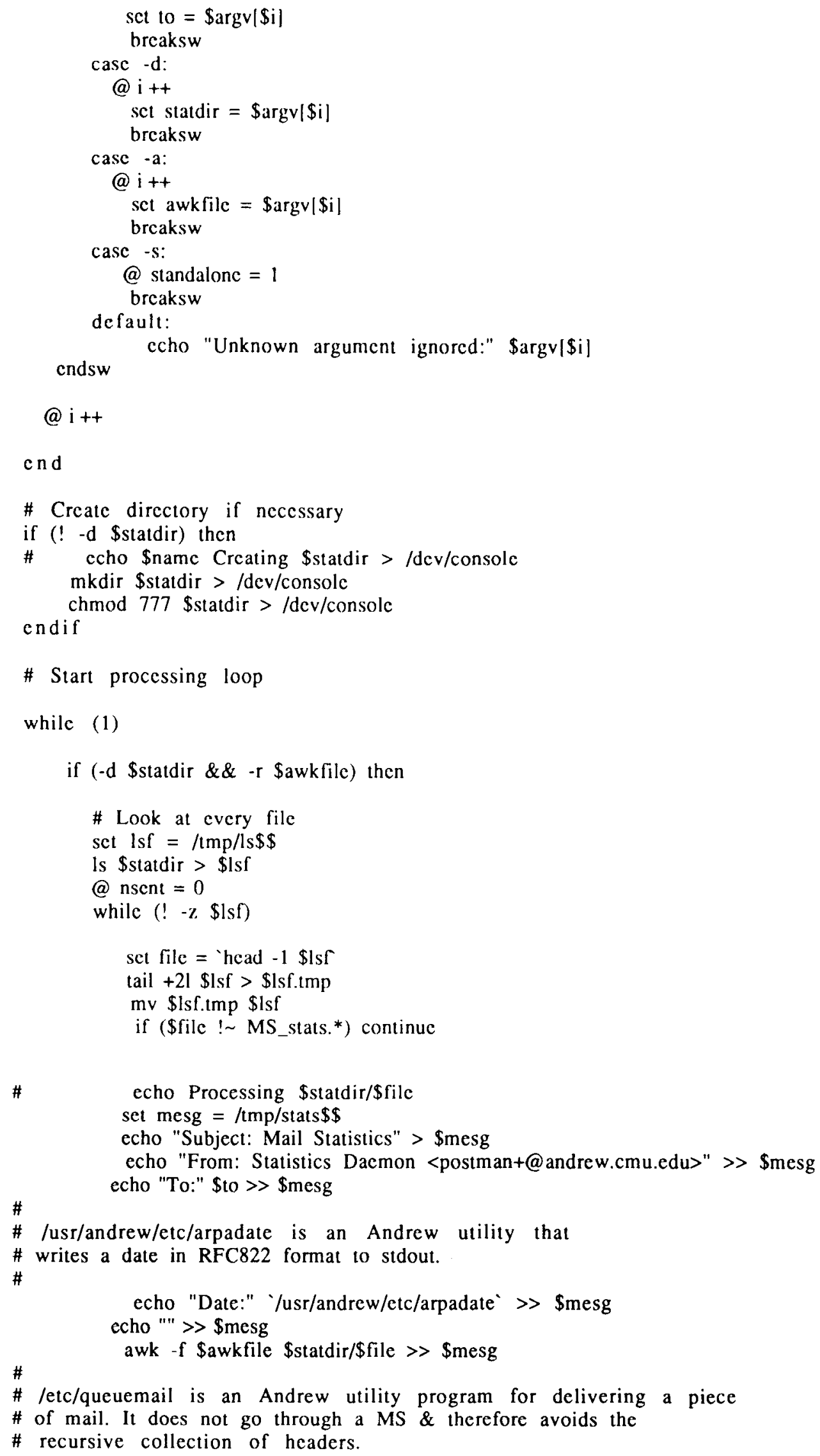




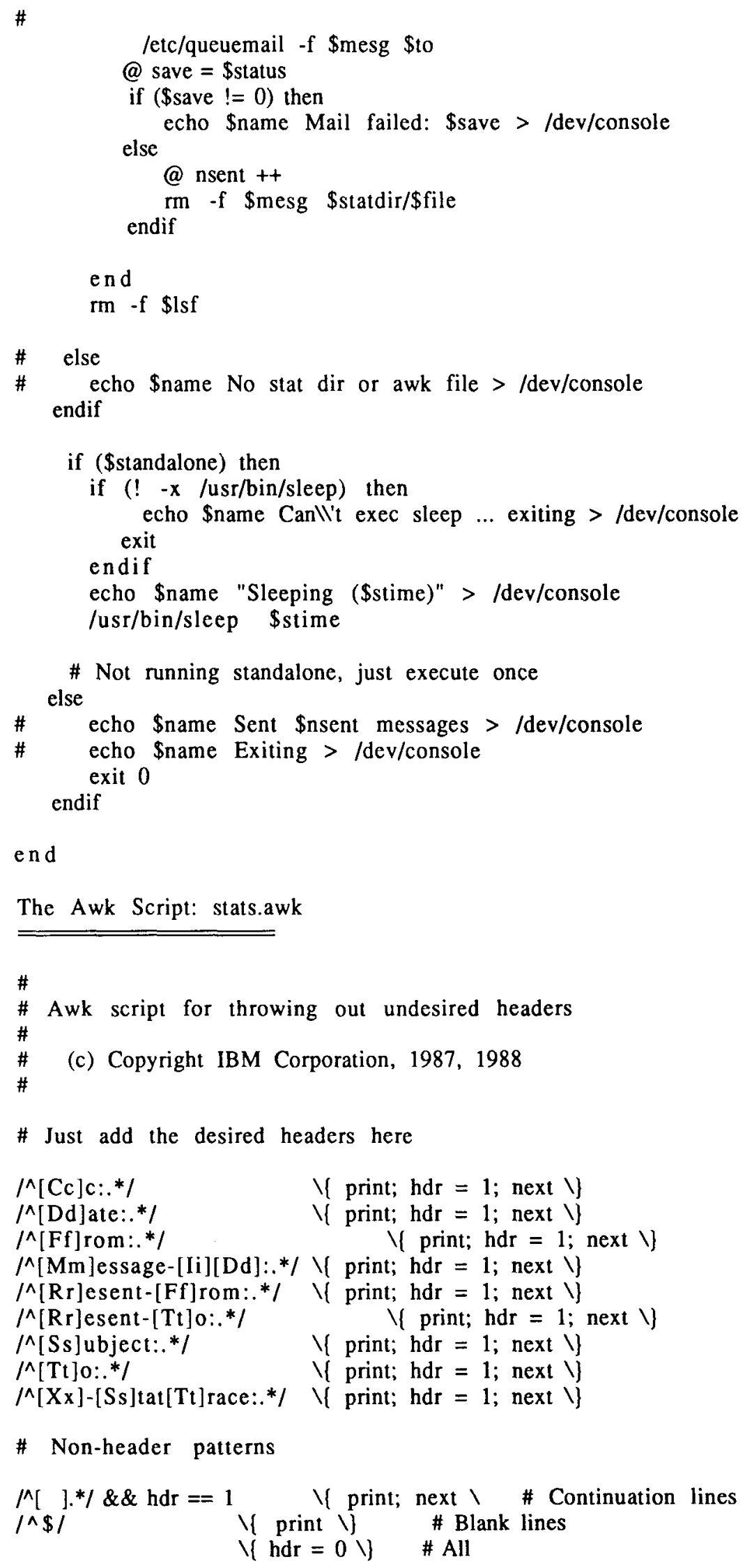

The Awk Script: stats.awk 